Classification

Physics Abstracts

$23.20 \mathrm{C}-23.90-27.90$

\title{
Two alpha, three alpha and multiple heavy-ion radioactivities
}

\author{
D. N. Poenaru and M. Ivaşcu \\ Institute for Physics and Nuclear Engineering, P.O. Box MG-6, R-76900, Bucharest, Romania
}

(Reçu le 25 mars 1985, accepté sous forme définitive le 30 avril 1985)

Résumé. - La possibilité de nouveaux modes de radioactivité par émission spontanée de deux ou trois particules $\alpha$ ou de deux ions lourds identiques ou différents est envisagée. La variante analytique du modèle de la fission super-asymétrique est utilisée pour estimer les durées de vie.

\begin{abstract}
New decay modes by spontaneous emission of two and three $\alpha$ particles and two identical or different heavy ions, are predicted. The analytical variant of the superasymmetric fission model is used to estimate the half lives.
\end{abstract}

The analytical variant of the superasymmetric fission model (ASAFM) was derived [1] in order to make a systematic search of new decay modes by spontaneous emission of heavy ions (HI) from all nuclides with known masses [2,3]. It is an efficient alternative of the other three calculation methods used for this purpose [4] and allows to calculate half lives and branching ratios relative to $\alpha$ decay, which are the quantities experimentally determined. ASAFM was extended [5] to account for the angular momentum and small excitation energy effects. Stability relative to the emission of ${ }^{2,3} \mathrm{H},{ }^{3} \mathrm{He},{ }^{4} \mathrm{Li},{ }^{7} \mathrm{~B},{ }^{9} \mathrm{C}$ [1] and ${ }^{6-10} \mathrm{He}$ [5] have been found. Then it was used, step by step to predict [5-9] new decay modes (see also [10-14] and the review paper [15]). From 8 modes in 1980 we arrived with more than 150 in 1984 [8, 9].

An important conclusion obtained very clearly for ${ }^{5} \mathrm{He}$ [5] and which is confirmed for the other modes is : the maximum emission rate is obtained for the double magic-daughter ${ }^{208} \mathrm{~Pb}$ or not too far from it.

Two of these modes are already experimentally confirmed $:{ }^{14} \mathrm{C}$ radioactivity of ${ }^{223} \mathrm{Ra}[17$ 21] and of ${ }^{222,224} \mathrm{Ra}$ [20]; ${ }^{24} \mathrm{Ne}$ radioactivity of ${ }^{232} \mathrm{U}$ [21] and of ${ }^{231} \mathrm{~Pa}$ [23]. A superasymmetric fission model based on the proximity + Coulomb potential was derived by Shi and Swiatecki [24].

The shortcomings of penetrability calculations are analysed in reference [10] in comparison with lifetimes.

Better agreement with $\alpha$-decay half lives of 380 emitters and the reproduction of ${ }^{14} \mathrm{C}$ radioactivity of ${ }^{223} \mathrm{Ra}$ and of the $U$ isotopes spontaneous fission, has been obtained $[8,9]$ by introducing shell effects in the zero point vibration energy, $E_{\mathrm{v}}$ :

$$
E_{\mathrm{v}}=Q\left[0.056+0.039 \exp \left(\frac{4-A_{2}}{2.5}\right)\right] ; \quad Q>0, \quad A_{2} \geqslant 4 .
$$

The relationship (1) and the equations from reference [5] (where by misprint the numerical coefficient of $K_{\mathrm{ov}}$ was written 0.1296 instead of 0.2196 ) was used [16] to get a new table super- 
seding tables 2 of reference [7] and table 6 of reference [15] and will be used in the following, to estimate the half lives for new decay modes :

$$
A_{Z} \rightarrow A_{1} Z_{1}+A_{2} Z_{2}+A_{3} Z_{3}+\cdots
$$

by emission of several heavy ions $\left(A_{2}, Z_{2}, A_{3}, Z_{3}, \ldots\right)$ simultaneously. The daughter (heavy fragment) is $\left(A_{1} Z_{1}\right)$.

Like the diproton [25-27], dineutron [28-30] and trineutron [31] the complex $\left(A_{2}^{\prime}, Z_{2}^{\prime}\right)$, where $A_{2}^{\prime}=A_{2}+A_{3}+\cdots$ and $Z_{2}^{\prime}=Z_{2}+Z_{3}+\cdots$ is not a stable nucleus, but one can imagine a mechanism in which the particles during formation pass the potential barrier and after tunnelling they move apart [32]. Of course, in this case, the released energy $Q=M-\left(M_{1}+M_{2}+M_{3}+\cdots\right)$ will be shared between more than 2 fragments and the kinetic energy spectrum of the emitted particles will be more complicated than a simple « line » obtained when a single HI is emitted.

The group of HI has usually, the mass defect larger than the mass defect of the corresponding single nuclide, leading to smaller $Q$-value and consequently to longer half lives (smaller emission rates). On the contrary, for ${ }^{8} \mathrm{Be}$ (which is known to fission in two alpha particles) the opposite is true. Hence one can expect slightly decreased half lives for $2 \alpha$ emission in comparison with ${ }^{8} \mathrm{Be}$ radioactivity, which were estimated [6-9] to be rather good.

The results for some of the most favourable cases are presented in table I. Also the branching ratios relative to $\alpha$ decay are plotted in figure 1 for $2 \alpha$ and $3 \alpha$ radioactivities, and in figure 2 for the groups : $\alpha+{ }^{12} \mathrm{C}, \alpha+{ }^{13} \mathrm{C}$ and $\alpha+{ }^{14} \mathrm{C}$. The dotted line is drawn at the position of the magic number of neutrons (126) of the daughter.

Heavy-ion branching ratios as low as $10^{-13}$ have turned out to be detectable experimentally. Since the predictions for the $2 \alpha$ mode in isotopes of $\mathrm{Ac}, \mathrm{Th}, \mathrm{Pa}$ are of the same order of magnitude, it seems conceivable that a detection method can be devised, although competition with ${ }^{8} \mathrm{Be}$ and even ${ }^{12} \mathrm{C}$ is to be envisaged. Other predicted processes such as the emission of $3 \alpha$ and $\alpha+\mathrm{HI}$ will be very much lower in intensity unless much more favourable combinations are found. The best chance of seeing these processes seems to be from the decay of excited levels $(5,8)$ such as in beta-delayed heavy-ion emission.

Table I. - Emission of multiple heavy ions from some parent nuclides compared with other competing processes.

\begin{tabular}{|c|c|c|c|c|c|c|c|c|c|}
\hline \multirow{2}{*}{$\begin{array}{c}\text { Parent } \\
\text { nucleus }\end{array}$} & \multirow{2}{*}{$\begin{array}{c}\log T_{t} \\
(\mathrm{~s})\end{array}$} & $\begin{array}{c}\log T_{\alpha} \\
\text { (s) }\end{array}$ & \multicolumn{4}{|c|}{ Emitted multiple HI } & \multicolumn{3}{|c|}{ Single HI in competition } \\
\cline { 4 - 9 } & & Group & $Q(\mathrm{MeV})$ & $\log T(\mathrm{~s})$ & $\log \left(T / T_{\alpha}\right)$ & $\mathrm{HI}$ & $Q(\mathrm{MeV})$ & $\log T(\mathrm{~s})$ \\
\hline${ }^{219} \mathrm{Ac}$ & -5.15 & -5.15 & $2 \alpha$ & 18.4 & 9.6 & 14.7 & ${ }^{8} \mathrm{Be}$ & 18.3 & 9.8 \\
${ }^{220} \mathrm{Ac}$ & -1.59 & -0.97 & & 17.5 & 11.6 & 12.6 & ${ }^{8} \mathrm{Be}$ & 17.4 & 11.9 \\
${ }^{220} \mathrm{Th}$ & -5.01 & -5.01 & & 18.5 & 10.0 & 15.0 & ${ }^{8} \mathrm{Be}$ & 18.4 & 10.2 \\
${ }^{221} \mathrm{Th}$ & -2.77 & -2.54 & & 17.8 & 11.6 & 14.2 & ${ }^{12} \mathrm{C}$ & 33.3 & 11.7 \\
${ }^{222} \mathrm{~Pa}$ & -2.24 & -1.94 & & 18.1 & 11.6 & 13.5 & ${ }^{12} \mathrm{C}$ & 33.9 & 11.4 \\
${ }^{223} \mathrm{~Pa}$ & -2.19 & -1.84 & $3 \alpha$ & 26.7 & 26.2 & 28.1 & ${ }^{12} \mathrm{C}$ & 34.0 & 11.3 \\
${ }^{225} \mathrm{~Pa}$ & 0.26 & 0.41 & $\alpha+{ }^{12} \mathrm{C}$ & 40.2 & 28.2 & 27.8 & ${ }^{15} \mathrm{~N}$ & 40.2 & 15.4 \\
${ }^{225} \mathrm{Th}$ & 2.68 & 3.07 & $\alpha+{ }^{13} \mathrm{C}$ & 33.5 & 31.7 & 28.6 & ${ }^{14} \mathrm{C}$ & 31.7 & 16.9 \\
${ }^{226} \mathrm{Th}$ & 3.27 & 3.39 & $\alpha+{ }^{14} \mathrm{C}$ & 39.5 & 30.8 & 27.4 & ${ }^{18} \mathrm{O}$ & 45.7 & 18.9 \\
${ }^{221} \mathrm{Ra}$ & 1.45 & 1.92 & $\alpha+{ }^{9} \mathrm{Be}$ & 20.9 & 42.2 & 40.3 & ${ }^{14} \mathrm{C}$ & 32.4 & 13.8 \\
${ }^{232} \mathrm{Pu}$ & 3.16 & 4.01 & $2\left({ }^{12} \mathrm{C}\right)$ & 60.1 & 48.3 & 44.3 & ${ }^{26} \mathrm{Mg}$ & 78.4 & 20.8 \\
${ }^{233} \mathrm{Am}$ & 2.56 & 3.60 & $2\left({ }^{12} \mathrm{C}\right)$ & 61.4 & 47.5 & 43.9 & ${ }^{26} \mathrm{Mg}$ & 79.5 & 20.8 \\
${ }^{235} \mathrm{~Np}$ & 7.53 & 12.66 & $2\left({ }^{14} \mathrm{C}\right)$ & 56.0 & 59.4 & 46.8 & ${ }^{28} \mathrm{Mg}$ & 77.1 & 21.8 \\
${ }^{236} \mathrm{Pu}$ & 7.96 & 8.10 & $2\left({ }^{14} \mathrm{C}\right)$ & 58.6 & 55.7 & 47.6 & ${ }^{28} \mathrm{Mg}$ & 79.7 & 19.8 \\
\hline
\end{tabular}




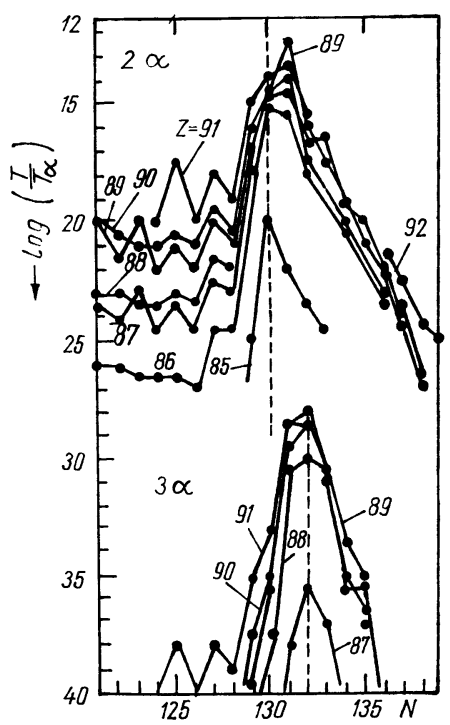

Fig. 1. - Branching ratios relative to the $\alpha$ decay for $2 \alpha$ and $3 \alpha$ radioactivities versus the neutron number of the parent nucleus.

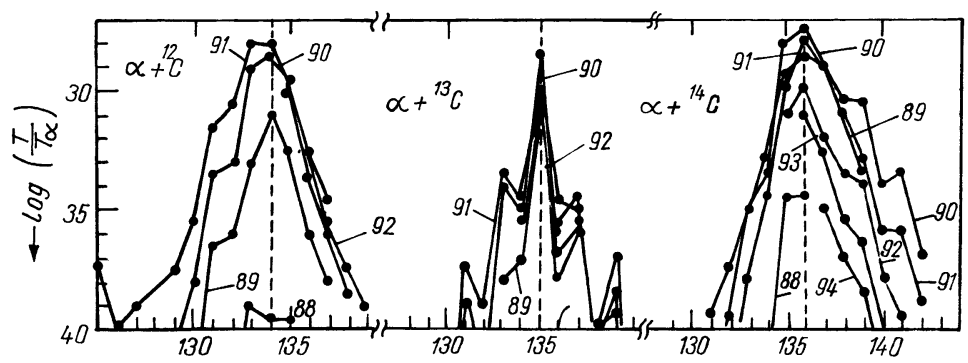

Fig. 2. - Branching ratios relative to the $\alpha$ decay for multiple $\mathrm{HI}$ emissions : $\alpha+{ }^{12} \mathrm{C}, \alpha+{ }^{13} \mathrm{C}$ and $\alpha+{ }^{14} \mathrm{C}$.

\section{References}

[1] Poenaru, D. N. and Ivascu, M., Central Institute of Physics, Bucharest, Report NP-17, 1980 ; Proceedings of the International School on Heavy Ion Physics, Poiana Brasov, 1980, p. 743.

[2] Wapstra, A. H. and Bos, K., Atom. Data Nucl. Data Tables 19 (1977) 215.

[3] Wapstra, A. H. and Audi, G., 7th Conf. on Atomic Masses and Fundamental Constants, Darmstadt, Sept. 3-7, 1984 ; Nucl. Phys. A, to be published.

[4] Sandulescu, A., Poenaru, D. N. and Greiner, W., E. Ch. A. Ya. 11 (1980) 1334 [Sov. J. Part Nucl. 11 (1980) 528].

[5] Poenaru, D. N. and Ivaşcu, M., Central Institute of Physics Bucharest, Report NP-27, 1983 ; $J$. Physique 45 (1984) 1099.

[6] Poenaru, D. N. and Ivaşcu, M., Rev. Roum. Phys. 29 (1984) 623.

[7] Poenaru, D. N., Ivaşcu, M., Sandulescu, A. and Greiner, W., J. Phys. G 10 (1984) L-183 ; Izvestia AN SSSR, Ser. Fiz. 48 (1984) 1897; JINR Dubna Report P4-84-326, 1984. 
[8] Poenaru, D. N. and Ivascu, M., Central Institute of Physics, Bucharest, Report NP-39, 1984 ; Lecture presented at the International School on Heavy Ion Physics, Poiana Brasov, September 1984.

[9] Poenaru, D. N., Ivaşcu, M., Sandulescu, A. and Greiner, W., JiNR Dubna Report E4-84-811, 1984 : Phys. Rev. $C$, to be published.

[10] Poenaru, D. N., Ivaşcu, M., Sandulescu, A. and Greiner, W., JiNR Rapid Communications, No. 5 (1984) 29.

[11] Greiner, W., Ivaşcu, M., Poenaru, D. N. and Sandulescu, A., Z. Phys. A 320 (1985) 347.

[12] Sandulescu, A., Poenaru, D. N., Greiner, W. and Hamilton, J. H., Phys. Rev. Lett. 54 (1985) 490.

[13] Bromley, D. A., 4th Int. Conf. on Clustering Aspects of Nucl. Structure and Nucl. Reactions, Chester (England) July 23-27, 1984.

[14] Hamilton, J. H., Hansen, P. G. and Zganjar, E. F., Rep. Progr. Phys., to be published.

[15] Poenaru, D. N., Ivascu, M., Sandulescu, A. and Greiner, W., JinR Dubna Report E4-84-446, 1984.

[16] Poenaru, D. N., Ivaşcu, M., Sandulescu, A. and Greiner, W., Central Institute of Physics, Bucharest, Report NP-41, 1985. Rev. Roum. Phys., to be published.

[17] Rose, H. J. and Jones, G. A., Nature 307 (1984) 245.

[18] Alexandrov, D. V., Beliatsky, A. F., Glukhov, Yu. A., Nikolsky, E. Yu., Novatsky, B. G., Ogloblin, A. A. and Stepanov, D. N., Pisma v JETP 40 (1984) 152.

[19] Gales, S., Hourani, E., Hussonois, M., Schapira, J. P., Stab, L. and Vergnes, M., Phys. Rev. Lett. 53 (1984) 759 ; AMCO, Darmstadt, 2-7 September, 1984.

[20] Price, P. B., Stevenson, J. D., Barwick, S. W., Ravn, H. L., Phys. Rev. Lett. 54 (1985) 297.

[21] Kutschera, W., Amhad, I., Armato III, S. G., Friedman, A. M., Gindler, J. E., Henning, W., IshiI, T., Paul, M. and ReHM, K. E., Phys. Rev. C, to be published.

[22] Barwick, S. W., Price, P. B. and Stevenson, J. D., Phys. Rev. Lett., to be published.

[23] Sandulescu, A., Zamiatnin, Yu. S., Lebedev, I. A., Miasoedov, B. F., Tretyakova, S. P. and HaseGAN, D., JINR Rapid Communications, No. 5 (1984) 5.

[24] SHI Yi-Jin and SWIATECKI, W. J., Phys. Rev. Lett. 54 (1985) 300.

[25] Goldansky, V. I., JETP 39 (1960) 497 ; Nucl. Phys. 19 (1960) 482.

[26] Cable, M. D., Honkanen, J., Parry, R. F., Zhou, S. H., Zhou, Z. Y. and Cerny, J., Phys. Rev. Lett. 50 (1983) 404.

[27] Honkanen, J., Cable, M. D., Parry, R. F., Zhou, S. H., Zhou, Z. Y. and Cerny, J., Phys. Lett. $B 133$ (1983) 146.

[28] Berlovich, E. E., Golubev, O. M. and Novikov, Yu. N., Pisma v JETP 12 (1970) 289.

[29] Azuma, R. E., Carraz, L. C., Hansen, P. G., Jonson, B., Kratz, K. L., Mattsson, S., Nyman, G., Ohm, H., Ravn, H. L., Schroder, A. and Ziegert, W., Phys. Rev. Lett. 43 (1979) 1652.

[30] Detraz, C. et al., Phys. Lett. B 94 (1980) 307.

[31] Azuma, R. E., Bjornstad, T., Gustafsson, H. A., Hansen, P. G., Jonson, B., Mattsson, S., Nyman, G., Poskanzer, A. M. and Ravn, H. L., Phys. Lett. B 96 (1980) 31.

[32] Poenaru, D. N. and IvaşCU, M., Central Institute of Physics, Bucharest, Report NP-40, 1984. 